\title{
ANALISIS PENGUASAAN KONSEP DAN SIKAP REMAJA SEKOLAH TERHADAP KESEHATAN REPRODUKSI
}

\author{
Maesaroh, Eka Kartikawati dan Devi Anugrah \\ Unuversitas Muhammadiyah Prof. Dr. HAMKA (UHAMKA) \\ Email: maesyaroh@uhamka.ac.id, eka.kartikawati@uhamka.ac.id dan \\ devi.anugerah@uhamka.ac.id
}

\begin{abstract}
Around 60 million people in Indonesia are at a young age. This potential determines the progress and character of the nation in the future. Globalization, can gives positive and negative impacts on the growth and development of the younger generation. One of negative impact such as deviant sexual behavior that occurs in various parts of the world which is then known and can be imitated by young people in Indonesia. This research is motivated by the many young people who feel taboo when talking or asking about reproductive health. This can be caused by parents who feel ashamed, consider it not important or do not clearly explain reproductive health to children. This research aims to detect the understanding and opinions of school adolescents about the concept of reproductive health. The method in this research is descriptive with a quantitative approach. The results of the research are $69.9 \%$ of teenage students who already know the basic concepts of reproduction in adolescents. There were $30.1 \%$ among the research samples who did not know the basic concept of reproduction. The percentage of female school adolescents is better at understanding reproductive health knowledge. Around 1.8-11.5\% of adolescents expressed an agreed attitude towards premarital sexual behavior and sexual abuse.
\end{abstract}

Keywords: school teenagers, reproduction health and sexual deviant behavior

\section{Abstrak}

Sekitar 60 juta jumlah penduduk di Indonesia berada pada usia muda. Potensi ini sangat menentukkan kemajuan dan karakter bangsa di masa depan. Globalisasi, dapat memberikan dampak positif maupun negative terhadap pertumbuhan dan perkembangan generasi muda. Salah satu dampak negatif misalnya perilaku seksual menyimpang yang terjadi di berbagai belahan dunia yang kemudian diketahui dan dapat ditiru oleh kalangan muda di Indonesia. Penelitian ini dilatarbelakangi oleh banyaknya kalangan muda yang merasa tabu membicarakan atau bertanya terkait dengan kesehatan reproduksi. Hal tersebut dapat disebabkan orang tua yang merasa malu, menganggap tidak penting atau tidak secara jelas menjelaskan kesehatan reproduksi kepada anak. Penelitian ini bertujuan untuk mendeteksi pemahaman dan pendapat remaja sekolah tentang konsep kesehatan reproduksi. Metode dalam penelitian ini yaitu deskriptif dengan pendekatan kuantitatif. Hasil penelitian yaitu 69,9\% remaja pelajar telah mengetahui konsep dasar reproduksi pada remaja. Terdapat $30,1 \%$ diantara sampel penelitian yang tidak mengetahui konsep dasar 
reproduksi. Remaja sekolah perempuan secara persentase lebih baik dalam memahami pengetahuan kesehatan reproduksi. Sekitar $1,8-11,5 \%$ remaja menyatakan sikap setuju terhadap perilaku seksual pranikah dan penyimpangan seksual.

Kata kunci: remaja sekolah, kesehatan reproduksi, perilaku penyimpangan seksual

\section{Pendahuluan}

Badan Kependudukan dan Keluarga Berencana (BKKBN) menyatakan bahwa yang termasuk kategori remaja yaitu rentang usia 10-24 tahun dan belum menikah. Remaja merupakan tahapan usia yang pada umumnya seseorang mengalami kematangan reproduksi secara fisik maupun psikologi. Pengetahuan tentang kesehatan reproduksi dalam kehidupan sehari-hari dapat menunjang pola hidup reproduksi yang sehat. Menurut WHO individu yang dapat menentukan waktu dan cara melakukan reproduksi merupakan makna dari kesehatan reproduksi. Terjadinya proses reproduksi yang terlalu cepat misalnya melalui pernikahan dini, disebabkan kurangnya pengetahuan remaja tentang kesehatan reproduksi (Puspikawati \& Megatsari, 2019).

Permasalahan kesehatan reproduksi pada remaja mencakup kurangnya informasi yang akurat mengenai reproduksi sehat, pelayanan kesehatan dan peratutan perundangundangan yang kurang mendukung (Kartikasari et al., 2019). Banyak remaja memiliki hubungan yang kurang stabil dengan orangtua maupun orang dewasa lainnya merupakan penyebab mereka tidak memeroleh informasi akurat tentang kesehatan reproduksi. Kurangnya akses terhadap pelayanan kesehatan reproduksi yang terjangkau dan terjamin kerahasiaannya juga semakin membatasi akses mereka untuk mendapat informasi yang tepat tentang kesehatan reproduksi (Maesaroh et al., 2019). Hal tersebut selaras dengan hasil penelitian (Fatimah et al., 2019) bahwa remaja lebih merasa nyaman bercerita tentang masalah kesehatan reproduksi kepada teman. Hasil penelitian (Ernawati, 2018) menyatakan bahwa yang memengaruhi pengetahuan kesehatan reproduksi remaja pada kategori baik salah satunya yaitu pemanfaatan orangtua sebagai sumber informasi. Banyaknya resiko pada kesehatan reproduksi khususnya remaja sekolah mendorong kami untuk melakukan analisis tentang penguasaan konsep dan sikap remaja sekolah terhadap kesehatan reproduksi di wilayah kabupaten Bekasi.

\section{Metode Penelitian}

Penelitian dilaksanakan secara deskriptif untuk memperoleh gambaran tentang pengetahuan dan sikap remaja sekolah di kabupaten Bekasi sesuai dengan keadaan sebenarnya (Soendari, 2010). Pendekatan kuantitatif dilakukan untuk memperoleh data primer hasil penelitian dalam bentuk angka (Mulyadi, 2013). Sampel penelitian sebanyak 167 orang remaja sekolah tersebar di lima SMA dan SMK negeri maupun swasta dengan kelas X, XI, dan XII di Kabupaten Bekasi. 


\section{Hasil dan Pembahasan}

Pada bagian ini berisi tentang tingkat pengetahuan reproduksi pada remaja yang diperoleh melalui hasil kuesioner. Secara keseluruhan kuesioner berisi 10 pernyataan positif maupun negatif yang harus diisi responden remaja untuk diketahui tingkat pengetahuannya tentang reproduksi pada perempuan dan laki-laki. Berdasarkan 174 orang remaja sekolah di Bekasi yang telah menjadi responden, berikut data tingkat pengetahuan remaja tentang reproduksi.

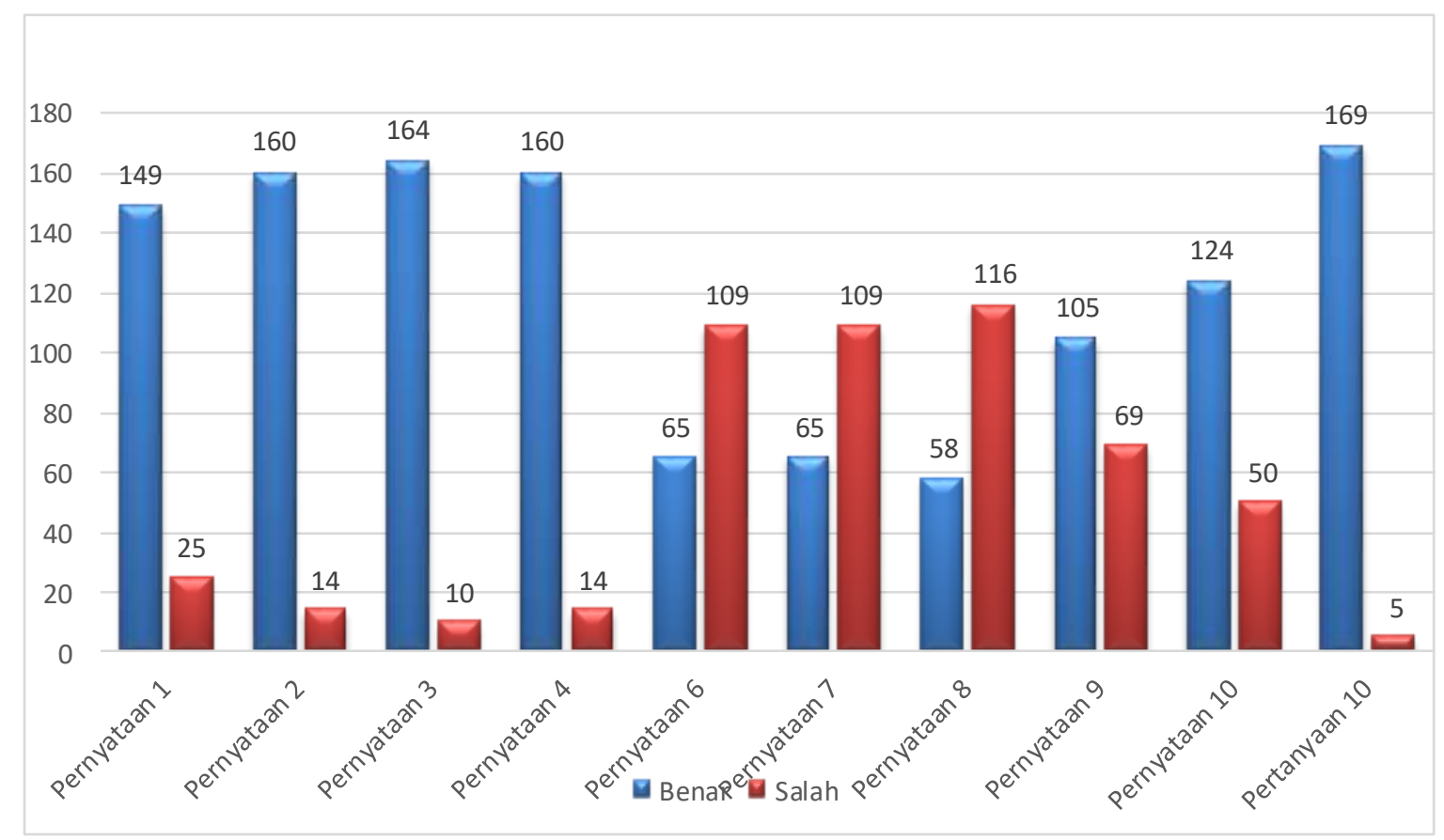

\section{Gambar 1 Tingkat Pengetahuan Reproduksi Remaja Sekolah}

Berdasarkan data grafik di atas diketahui bahwa pada pernyataan 1) sebanyak $86 \%$ remaja telah mengetahui bahwa mimpi basah adalah salah satu ciri seks primer pada remaja laki-laki dan sebanyak $14 \%$ belum mengetahuinya. Pada pernyataan 2) sebanyak $92 \%$ remaja menjawab dengan benar tentang ciri-ciri seks primer pada remaja perempuan, namun masih terdapat $8 \%$ remaja pelajar yang tidak menjawab dengan benar. Pada pertanyaan ke -3 sebanyak $94 \%$ remaja sekolah menjawab dengan benar tentang definisi menstruasi dan 6\% sisanya menjawab salah. Pada pernyataan 4) sebanyak $92 \%$ remaja sekolah menjawab benar bahwa perkembangan organ reproduksi mereka memengaruhi hormone dan ketertarikan terhadap lawan jenis sedangkan $8 \%$ sisanya tidak mengetahui hal tersebut. Sebanyak $37 \%$ remaja mengetahui fungsi seksual remaja perempuan relatif lebih cepat matang dari pada remaja laki-laki, sedangkan $63 \%$ remaja sisanya menjawab salah pernyataan 5). Pada pernyataan 6) hanya 37\% remaja sekolah yang mengetahui bahwa masturbasi merupakan perilaku seks pranikah beresiko dan $63 \%$ remaja tidak mengetahuinya. Pada pernyataan 7) sebanyak 33\% remaja menyatakan benar bahwa perilaku berkencan, berpegangan tangan dengan lawan jenis 
termasuk jenis seks pranikah, dan $67 \%$ sisanya berpendapat salah atau tidak menyetujui pernyataan tersebut. Remaja sekolah sebanyak 60\% dinyatakan mengetahui bahwa melakukan hubungan seks dapat menyebabkan kehamilan walau hanya sekali, namun sisanya sebanyak $40 \%$ tidak membenarkan pernyataan 8) tersebut. Pada pernyataan 9) diketahui sebanyak 71\% remaja mengetahui bahwa penyakit HIV dan AIDS merupakan salah satu dampak dari perilaku seks pranikah, dan $29 \%$ sisanya tidak mengetahui hal tersebut. Pada pernyataan ke 10) diketahui bahwa sebanyak 97\% remaja mengetahui perilaku berganti pasangan seks dapat menyebabkan HIV dan AIDS sedangkan 3\% remaja sisanya menjawab salah pada pernyataan tersebut.

Pada hasil penelitian diketahui lebih dari separuh sampel populasi atau tepatnya 69,9\% remaja pelajar di Bekasi telah menguasai dengan baik konsep dasar reproduksi pada remaja. Hal ini hamper sama dengan penelitian (Firdaus \& Astutik, 2019) bahwa $68 \%$ remaja perempuan tingkat SMP memiliki pengetahuan baik tentang kesehatan reproduksi perempuan. Namun masih terdapat 30,1\% diantara sampel penelitian yang tidak mengetahui beberapa konsep dasar reproduksi. Misalnya untuk ciri-ciri seks primer pada laki-laki, terdapat $14 \%$ sampel yang tidak mengetahui sedangkan pada ciri perkembangan seks primer pada remaja perempuan terdapat $8 \%$ saja pelajar yang menjawab salah. Hal ini diasumsikan terjadi pada sampel yang menjawab salah pernyataan tersebut karena mereka berjenis kelamin perempuan untuk pernyataan ciri seks pada remaja laki-laki dan begitu juga sebaliknya untuk ciri perkembangan seks pada remaja perempuan. Remaja perempuan maupun laki-laki tersebut menjawab salah karena mereka tidak mengalami dalam kehidupan sehari-hari sehingga mereka melupakan konsep tanda-tanda perkembangan seks primer pada laki-laki maupun perempuan.

Pada pernyataan tentang definisi menstruasi dan pengaruh perkembangan organ seksual terhadap minat remaja kepada lawan jenis yang terdapat pada nomor 3 dan 4 hampir seluruh sampel remja menjawab dengan benar yaitu sebanyak 94\% dan $92 \%$. Saat mengetahui makna tentang mesntuasi, diharapkan remaja dapat menjaga kebersihan organ reproduksi saat menstruasi (Nurulicha, 2019). Berbeda halnya dengan pernyataan nomer 5 dan 6 hanya 37\% remaja yang menjawab benar, lebih dari setengah sampel remaja sekolah tidak mengetahui bahwa masturbasi dan onani merupakan perilaku seks pranikah yang beresiko. Ketidaktahuan remaja tersebut dapat berpengaruh terhadap perilaku seksual mereka, remaja dapat melakukan kegiatan masturbasi atau onani karena mereka menganggap kegiatan tersebut tidak beresiko bagi kesehatan dan kehidupan mereka. Hal tersebut tidak benar, masturbasi yang dilakukan perpempuan dan laki-laki memiliki resiko kesehatan apalagi bagi yang belum menikah, dapat berupa: a) menimbulkan nyeri pada kelamin luar, b) merusak selaput dara, c) melemahkan syahwat atau hipoten saat telah berumah tangga, d) menganggu ejakulasi secara normal, e) menurunkan kecerdasan otak baik hard skills maupun soft skills karena selalu berkhayal atau berpikiran jorok, f) lemahnya daya tahan tubuh jika terlalu banyak keluar sperma, g) kemungkinan terserang kanker prostat di usia senja semakin besar, h) dapat mengalami insomnia, i) pada tahap kronis dapat terjadi sperma keluar dengan sendirinya 
saat mereka menahan atau tidak melakukan onani, hal ini terjadi karena sudah otak sudah tidak dapat mengontrolnya, j) karakter tempramental atau gampang marah, umumnya dilampiaskan dengan onani/masturbasi, dan k) menganggu kehidupan sosial.

Berdasarkan data kuesioner selanjutnya, 67\% remaja menganggap perilaku berkencan, berpegangan tangan dengan lawan jenis bukan termasuk jenis seks pranikah. Selain itu, sebanyak $40 \%$ remaja sekolah membenarkan jika melakukan hubungan seks tidak menyebabkan kehamilan jika hanya satu kali. Sebanyak $29 \%$ remaja pelajar tidak mengetahui penyakit HIV dan AIDS dapat diakibatkan kegiatan seksual pranikah. Terdapat 3\% remaja sekolah tidak mengetahui kegiatan berganti pasangan seks tidak secara aman dapat tertular penyakit HIV dan AIDS.

Berdasarkan (BKKBN, 2006) hal di atas keliru. Bentuk perilaku seksual bermacam-macam mulai dari tahapan bergandengan tangan, berpelukan, bercumbu, bercumbu berat sampai dengan tahap kegiatan berhubungan seks. Selanjutnya dijelaskan bahwa perilaku seks yang tanpa mengakibatkan terjadinya pertukaran cairan vagina dengan cairan sperma merupakan perilaku seks aman, misalnya kategori bergandengan tangan, berpelukan, dan berciuman. Telah dijelaskan pula bahwa kegiatan seks tanpa menggunakan "pengaman" bukan termasuk perilaku seks aman dari kehamilan dan Penyakit Menular Seksual termasuk di dalamnya HIV dan AIDS.

Hasil kuesioner selanjutnya menunjukkan skala sikap remaja terhadap kesehatan reproduksi mereka. Terdapat 10 pernyataan yang digunakan untuk mengetahui kecenderungan sikap remaja laki-laki dan perempuan terhadap kesehatan reproduksi. Setiap pernyataan memiliki empat pilihan jawaban sikap yaitu: sangat tidak setuju (STS), tidak setuju (TS), setuju (S), dan sangat setuju (SS). Berikut merupakan hasil kuesioner pernyataan sikap remaja laki-laki dan perempuan terhadap kesehatan reproduksi.

Tabel 1 Data Skala Sikap Remaja terhadap Kesehatan Reproduksi

No.

Pernyataan

Persentase Jawaban

$(\%)$

\begin{tabular}{llll}
\hline STS & TS & S & SS
\end{tabular}

1. Hubungan seks boleh dilakukan sebelum menikah $\quad \begin{array}{lllll}66.5 & 28.8 & 2.9 & 1.8\end{array}$ asalkan suka sama suka

2. Setiap orang dapat melakukan hubungan seks berganti- $\begin{array}{lllll}68.0 & 30.2 & 1.7 & 0.0\end{array}$ ganti pasangan

3. Perempuan dan laki-laki harus menunggu dewasa dan $\quad \begin{array}{llll}2.9 & 1.2 & 41.0 & 54.9\end{array}$ menikah sebelum melakukan hubungan seksual

4. Tindakan aborsi/menggugurkan kandungan adalah dosa $11.5 \quad 5.2 \quad 23.6 \quad 59.8$

5. Pendidikan tentang kesehatan reproduksi tidak perlu $\quad \begin{array}{lllll}8.8 & 39.2 & 41.5 & 10.5\end{array}$ disampaikan di sekolah secara formal

6. Remaja boleh melakukan onani/masturbasi $\quad \begin{array}{llll}26.0 & 50.9 & 17.9 & 5.2\end{array}$

$\begin{array}{llllll}\text { 7. } & \text { Hubungan seks sebelum menikah merupakan pergaulan } & 52.7 & 36.1 & 7.7 & 3.6\end{array}$ modern 


\begin{tabular}{llllll}
\hline 8. & $\begin{array}{l}\text { Hubungan seks sebelum menikah adalah dosa bagi } \\
\text { agama yang kamu anut }\end{array}$ & 9.2 & 9.8 & 20.2 & 60.7 \\
\hline 9. & $\begin{array}{l}\text { Ciuman, belaian, dan pelukan dari seorang pacar } \\
\text { adalah ungkapan sayang }\end{array}$ & 39.7 & 41.4 & 13.2 & 5.7 \\
\hline 10. & $\begin{array}{l}\text { Untuk menjaga keutuhan hubungan, saya tidak akan } \\
\text { menghindari bila pacar melakukan perabaan pada } \\
\text { daerah erogen/erotis }\end{array}$ & 56.1 & 20.2 & 13.9 & 9.8 \\
\hline
\end{tabular}

Berdasarkan Tabel 1 dapat diketahui skala kecenderungan sikap remaja terhadap kesehatan reproduksi yaitu pada peryataan 1 dengan persentase 66,5\% menyatakan sangat tidak setuju jika hubungan seks dapat dilakukan sebelum menikah. Pada pernyataan 2 remaja menunjukkan sikap sangat tidak setuju dengan persentase $68 \%$ jika setiap orang dapat berganti-ganti pasangan dalam hubungan seks. Pada pernyataan ke 3 sebanyak 54,9\% remaja sekolah menyatakan sangat setuju dengan pernyataan perempuan dan laki-laki harus menunggu dewasa dan menikah. Pada pernyataan ke 4 sebanyak 59,8\% remaja sekolah menyatakan sangat setuju dengan pernyataan tindakan aborsi atau menggugurkan kandungan adalah dosa. Sebanyak 41,5\% remaja sekolah menyatakan setuju dengan pernyatan 5 bahwa pendidikan kesehatan reproduksi tidak perlu disampaikan di sekolah, sedangkan 39,2\% remaja menyatakan tidak setuju jika kesehatan reproduksi tidak perlu disampaikan di sekolah. Sebanyak 50,9\% remaja tidak menyetujui jika remaja dapat melakukan onani atau masturbasi yang diketahui melalui pernyataan 6. Pada pernyataan 7 sebanyak 52,7\% remaja bersikap sangat tidak setuju dengan kalimat hubungan seks sebelum menikah merupakan pergaulan modern. Pada pernyataan 8 yang berisi berhubungan seks sebelum menikah adalah dosa bagi agaman yang kamu anut, sebanyak 60,7\% remaja pelajar menyatakan sangat setuju. Pada pernyataan 9 sebanyak 41,4\% remaja bersikap tidak setuju bahwa ciuman, belaian, dan pelukan dari seorang pacar adalah ungkapan sayang, sedangkan pada persentase tertinggi ke dua yaitu sebanyak 39,7\% menyatakan sangat tidak setuju. Pada pernyataan ke 10 sebanyak 56,1\% remaja bersikap sangat tidak setuju pada pernyataan untuk menjaga keutuhan hubungan, saya tidak akan menghindari bila pacar melakukan perabaan pada daerah erogen.

Data penelitian tentang sikap remaja terhadap kesehatan reproduksi dapat mencerminkan perilaku seksual mereka dalam kehidupan sehari-hari. Berdasarkan KBBI (2017) sikap merupkan perbuatan yang berdasarkan pada pendirian dan keyakinan. Pernyataan sikap yang ditunjukkan remaja pada kuesioner penelitian merupakan pendirian dan keyakinan mereka terhadap suatu peristiwa.

Berdasarkan hasil penelitian pada Tabel 1 diketahui terdapat 1,8\% remaja sekolah di Bekasi menyatakan sikap sangat setuju jika hubungan seks boleh dilakukan sebelum menikah asalkan suka sama suka. Sejalan dengan hasil penelitian (Sanisahhuri, 2019) bahwa terdapat $58 \%$ siswa/ siswi tingkat SMA yang memiliki perilaku seksual ringan dan $48 \%$ diantaranya berpengetahuan kurang tentang eehatan reproduksi. Hal ini seyogyanya menjadi perhatian untuk orangtua, keluarga, guru di sekolah, dan 
masyarakat. Penyebab yang dapat memengaruhi sikap remaja merupakan kompilasi dari keluarga, landasan ajaran agama, dan lingkungan.

Terdapat 2,9\% sampel penelitian menyatakan sikap sangat tidak setuju jka perempuan dan laki-laki harus menunggu dewasa dan menikah sebelum melakukan hubungan seksual. Sebanyak $11,5 \%$ remaja menyatakan sangat tidak setuju dengan pernyataan tindakan aborsi atau menggugurkan kandungan adalah dosa. Selain itu, $10,5 \%$ remaja sangat setuju pendidikan tentang kesehatan reproduksi tidak perlu disampaikan di sekolah secara formal. Sebanyan 5,2\% remaja menyatakan sangat setuju pada pernyataan remaja boleh melakukan onani/masturbasi. Sejumlah 3,6\% remaja sangat setuju hubungan seks sebelum menikah merupakan pergaulan modern. Terdapat 9,2\% remaja menyatakan sangat tidak setuju hubungan seks sebelum menikah adalah dosa bagi agama. Selain itu, 5,7\% remaja bersikap sangat setuju jika ciuman, belaian, dan pelukan dari seorang pacar adalah ungkapan sayang. Sedangkan 9,8\% remaja menyatakan sangat setuju untuk menjaga keutuhan hubungan, saya tidak akan menghindari bila pacar melakukan perabaan pada daerah intim.

Hasil penelitian di atas menunjukkan proess telah terkikisnya rasa malu pada diri sebagian remaja sekolah. Salah satu penyebab degradasinya moral remaja yaitu pornografi yang dengan mudah dapat diakses. Paparan pornografi telah memberikan pengaruh terhadap jumlah remaja yang teridentifikasi mengalami penyimpangan seksual. Bangunan moral remaja dapat diluluhlantakkan dengan mudah oleh pornografi. Menurut (Isti, 2004) nafsu merupakan sumber energi yang mengerakkan manusia ke arah sifat kebinatangan. Namun Allah SWT menciptakan rasa malu dan akal untuk memelihara sifat kemanusiaan. Dengan akalnya, manusia dapat mengendalikan nafsu untuk meningkatkan kualitas hidup. Penanaman landasan agama kepada remaja sejak mereka kanak-kanak merupakan upaya sungguh-sungguh yang dapat dilakukan orangtua untuk membentengi hati, pikiran dan perilaku remaja dari perilaku seksual yang menyimpang. Agama merupakan peraturan berdimensi vertikal dan horizontal dari Tuhan Yang Maha Esa yang mampu memberi dorongan terhadap jiwa manusia yang berakal agar berpedoman menurut peraturan Tuhan dengan kehendaknya sendiri tanpa dipengaruhi (Sudarsono, 2004)

Lingkungan sekitar dapat memberikan dampak yang sangat besar terhadap sikap remaja terhadap kesehatan reproduksi. Melalui pendidikan reproduksi pengetahuan tentang kesehatan reproduksi remaja pra nikah dapat meningkat (Indah et al., 2018; Cahyani, 2019; Kismoyo, 2015). Pendidikan reproduksi pada remaja sangat efektif apabila disampaikan oleh orang terdekat mereka. Peran orangtua, masyarakat dan guru sebagai pembimbing sangat dibutuhkan dalam hal ini untuk mencegah perilaku penyimpangan seksual pada remaja.

\section{Kesimpulan}

Hasil penelitian menunjukkan sebanyak 69,9\% remaja pelajar di Bekasi telah mengetahui konsep dasar reproduksi pada remaja. Terdapat 30,1\% diantara sampel penelitian yang tidak mengetahui beberapa konsep dasar reproduksi. Remaja sekolah 
Maesaroh, Eka Kartikawati dan Devi Anugrah

perempuan secara persentase lebih baik dalam memahami pengetahuan kesehatan reproduksi. Hal ini sejalan dengan hasil survei demografi dan kesehatan Indonesia tahun 2017 bahwa kepedulianlaki-laki terhadap kesehatan reproduksi relative lebih rendah karena $72 \%$ pria kawin umur 15-54 merokok, $63 \%$ diantaranya merokok setiap hari. Sekitar 1,8-11,5\% remaja menyatakan sikap setuju terhadap perilaku seksual pranikah dan penyimpangan seksual. 


\section{BIBLIOGRAFI}

BKKBN. (2006). Buku Saku Bagi Petugas Lapangan Program KB Nasional Materi.

Ernawati, H. (2018). Pengetahuan kesehatan reproduksi remaja di daerah pedesaan. Indonesian Journal for Health Sciences, 2(1), 58-64.

Fatimah, S., Harahap, W., Pandiangan, A. T. M., \& Julianda, J. (2019). Pengaruh Pembentukan Peer Educator Terhadap Pengetahuan Kespro Pada Remaja. Prosiding Seminar Nasional: Pertemuan Ilmiah Tahunan Politeknik Kesehatan Karya Husada Yogyakarta, 1(1), 146-161.

Firdaus, H., \& Astutik, E. (2019). Gambaran Pengetahuan Sikap Dan Perilaku Personal Hygiene Organ Genitalia Eksterna Siswi Smp Di Kabupaten Banyuwangi Tahun 2017. Journal of Public Health Research and Community Health Development, 2(1), 52-59.

Indah, H. P., Andalas, U., Barat, S., Harly, K., Indah, P., \& Harlypratiwigmailcom, E. (2018). Efektifitas Konseling Kesehatan Reproduksi Terhadap Peningkatan Pengetahuan Kesehatan Reproduksi Pasangan Calon Pengantin di KUA Kota Padang Bagian Obstetri dan Ginekologi, Fakultas Kedokteran Universitas Andalas, Padang, Subbagian Obstetri Sosial , Ba. 2.

Isti, B. M. (2004). Remaja Dirantai Birahi (Kupas Tuntas Pornografi dalam Perspektif Islam). Pustaka Ulumudin.

Kartikasari, D., Ariwinanti, D., \& Hapsari, A. (2019). Gambaran pengetahuan kesehatan reproduksi siswa smk wisnuwardhana kota malang. Preventia, 1-6.

Maesaroh, M., Kartikawati, E., \& Anugrah, D. (2019). Perspektif Remaja Tentang Kesehatan Reproduksi Sebagai Upaya Pencegahan Penyimpangan Perilaku Seksual Di Kabupaten Bekasi. Florea: Jurnal Biologi Dan Pembelajarannya, 6(1), $36-44$.

Mulyadi, M. (2013). Penelitian Kuantitatif Dan Kualitatif Serta Pemikiran Dasar Menggabungkannya. Jurnal Studi Komunikasi Dan Media, 15(1), 128. https://doi.org/10.31445/jskm.2011.150106

Nurulicha, S. P. D. K. W. (2019). Perbedaan Pengetahuan, Sikap, Sumber Informasi Dan Faktor Lainnya Pada Personal Hygiene Saat Menstruasi. Jurnal Kesehatan Dan Kebidanan (Journal Of Health And Midwifery), 8(1), 1-13.

Puspikawati, S. I., \& Megatsari, H. (2019). Pengaruh Pendidikan Sebaya Terhadap Pengetahuan Kesehatan Repoduksi Remaja Di Karang Taruna Kabupaten Banyuwangi. Journal of Public Health Research and Community Health Development, 1(2), 80-88.

Soendari, T. (2010). Metode Penelitian Deskriptif. Metode Penelitian Deskriptif, 1-25. 
Maesaroh, Eka Kartikawati dan Devi Anugrah

Sudarsono. (2004). Kenakalan Remaja. PT. Rineka Cipta. 